\title{
As atividades produtivas nas microrregiões paranaenses
}

\author{
Augusta Pelinski \\ Jandir Ferrera de Lima ${ }^{* *}$ \\ Jefferson Andronio Ramundo Staduto ${ }^{* * *}$
}

RESUMO - O objetivo deste trabalho é analisar a concentração de determinadas atividades produtivas nas microrregiões do Paraná, identificando o grau de concentração e de reestruturação que ocorreu entre 1994 e 2003.

Palavras-chave: Desenvolvimento Econômico. Economia Regional. Economia Espacial.

\section{INTRODUÇÃO}

$\mathrm{Na}$ década de 1990, a economia paranaense ingressou em uma nova fase estimulada pela formação do polo automotivo, que se ampliou nos anos de 1990 com a vinda de montadoras e de suas fornecedoras; a modernização agropecuária e o cooperativismo; a ampliação quantitativa e qualitativa do complexo madeireiro e papeleiro; a expansão das atividades econômicas em regiões antes exclusivamente rurais; e o fortalecimento da infraestrutura (transportes, energia e telecomunicações) (LOURENÇO, 2002).

Frente a essa nova fase, este artigo analisa o perfil locacional de determinadas atividades produtivas nas microrregiões do Paraná, identificando o grau de concentração, especialização e a reestruturação dessas atividades, entre 1994 e 2003.

Para analisar a concentração de determinadas atividades produtivas nas microrregiões do Paraná utilizou-se do instrumental de análise regional, servindo-se das seguintes medidas ${ }^{1}$ : quociente locacional $(\mathrm{QL})$, coeficiente locacional (CL), coeficiente de especialização (CE) e de reestruturação (CR). Os dados foram coletados da RAIS, tendo como variável-base o emprego formal nas microrregiões paranaenses. Quanto mais dinâmica a economia regional, mais empregos ela gerará ao longo do tempo. Apesar das novas tecnologias poupadoras de mão-de-obra, uma economia depende em muito da demanda local e interregional para avançar. Com isso, ocorre o aumento na geração de empregos, o que

\footnotetext{
* Doutoranda em Economia do Desenvolvimento pela UFRGS. Endereço eletrônico: apelinski@gmail.com

** Doutor em Desenvolvimento Regional (Ph.D.) pela Université du Québec (UQAC)/Canadá. Professor do Mestrado em Desenvolvimento Regional e Agronegócio da UNIOESTE. Endereço eletrônico: jandir@unioeste.br

*** Doutor em Economia Aplicada pela USP. Professor do Mestrado em Desenvolvimento Regional e Agronegócio da UNIOESTE. Endereço eletrônico: staduto@unioeste.br

${ }_{1}^{1}$ Para maiores informações sobre essas medidas regionais consultar, entre outros, Costa (2002) e Haddad (1989).
} 
resulta em maior circulação de renda nas unidades familiares, acarretando numa maior demanda pelos bens e serviços locais e regionais.

As atividades produtivas analisadas se constituíram de sete ramos (Quadro 1), destacando que a composição das atividades pertencentes à indústria tradicional, indústria dinâmica e agroindústria, são do IBGE (2006) e as atividades pertencentes à indústria não tradicional seguiram a metodologia de Ferrera de Lima (2004).

QUADRO 1: CLASSFICAÇÃO DOS RAMOS DAS ATIVIDADES PRODUTIVAS

\begin{tabular}{|c|c|}
\hline Ramos & Descrição \\
\hline $\begin{array}{l}\text { Indústria } \\
\text { Tradicional }\end{array}$ & $\begin{array}{l}\text { Produtos alimentícios, vestuários/calçados, bebidas, madeira, têxtil, } \\
\text { mobiliário editora/gráfica. }\end{array}$ \\
\hline Indústria Dinâmica & $\begin{array}{l}\text { Fertilizantes/químicos, metalúrgicos, mecânica, material de transporte, } \\
\text { material elétrico/comunicação, papel e papelão. }\end{array}$ \\
\hline $\begin{array}{l}\text { Indústria Não } \\
\text { Tradicional }\end{array}$ & $\begin{array}{l}\text { Indústria produtora de minerais não metálicos, borracha, fumo, couro e } \\
\text { de construção civil. }\end{array}$ \\
\hline Agroindústria & $\begin{array}{l}\text { Abate e preparação de produtos de carne e pescado; lacticínio; ração; } \\
\text { processamento, preservação e produção de frutas, legumes, óleos e } \\
\text { gorduras; beneficiamento de produtos de origem vegetal, fabricação e } \\
\text { refino de óleo vegetal e das gorduras para alimentação; resfriamento e } \\
\text { preparação do leite e lacticínio; moagem e fabricação de produtos para } \\
\text { animais; indústria de açúcar, do café, outras indústrias alimentares; } \\
\text { fabricação de artigos de vestuário e acessórios; fabricação de calçados e } \\
\text { artigos de couro e peles; fabricação de produtos de madeira, destilação } \\
\text { de álcool; fabricação de artigos mobiliários. }\end{array}$ \\
\hline $\begin{array}{l}\text { Administração } \\
\text { Pública }\end{array}$ & --------- \\
\hline Comércio e Serviço & ----------- \\
\hline $\begin{array}{l}\text { Transporte e } \\
\text { Comunicação }\end{array}$ & ---------- \\
\hline
\end{tabular}

\section{PERFIL LOCACIONAL DAS ATIVIDADES PRODUTIVAS NO PARANÁ}

Um QL superior a unidade indica que a atividade, em determinada região, tem um padrão de localização mais significativo. Por isso, indica a especialização regional das atividades produtivas e sua tendência de concentração.

$\mathrm{Na}$ Figura 1, analisa-se o padrão de localização das indústrias tradicional, dinâmica e não tradicional. Observa-se que no ano de 1994, a grande maioria das microrregiões (66,7\%) detinha como indústria básica (de exportação) a tradicional, seguida, na mesma proporção (20,5\%), pela indústria dinâmica e pela não tradicional. Percebe-se que a grande maioria das microrregiões $(51,3 \%)$ possuía apenas uma indústria básica; 43,6\% das microrregiões concentravam, somente, a indústria tradicional; 5,1\% a indústria não tradicional e 2,6\% a indústria dinâmica.

80 
É possível constatar também, que 20,5\% das microrregiões não possuíam nenhuma concentração significativa de atividades de transformação, tendo pouca importância para o seu dinamismo. Destaca-se que somente na microrregião de São Mateus do Sul os três tipos de indústrias (dinâmica, tradicional e não tradicional) estavam presentes, refletindo flexibilidade quanto ao dinamismo de suas atividades e quanto ao seu próprio desenvolvimento.

No ano de 2003, a indústria tradicional continuou a se sobressair as demais indústrias, abrangendo $76,9 \%$ das microrregiões paranaenses. A indústria não tradicional concentrou-se em 25,6\% das microrregiões, seguida, por último, pela indústria dinâmica, com 17,9\% (figura 1). Esses dados indicam que a nova fase, relatada por Lourenço (2002), a qual o Paraná iria entrar nos anos de 1990 (principalmente do polo automobilístico, madeira e papelão, transportes, energia e telecomunicação, setores que compõe a indústria dinâmica), não se deu homogeneamente em todas as microrregiões e, a princípio, se deu nas regiões em que já existia tal indústria como motora.

FIGURA 1: QL MAIOR QUE UM, INDICANDO AS ATIVIDADES VOLTADAS PARA A EXPORTAÇÃO NAS MICRORREGIÕES DO PARANÁ-1994 (A), 2003 (B)

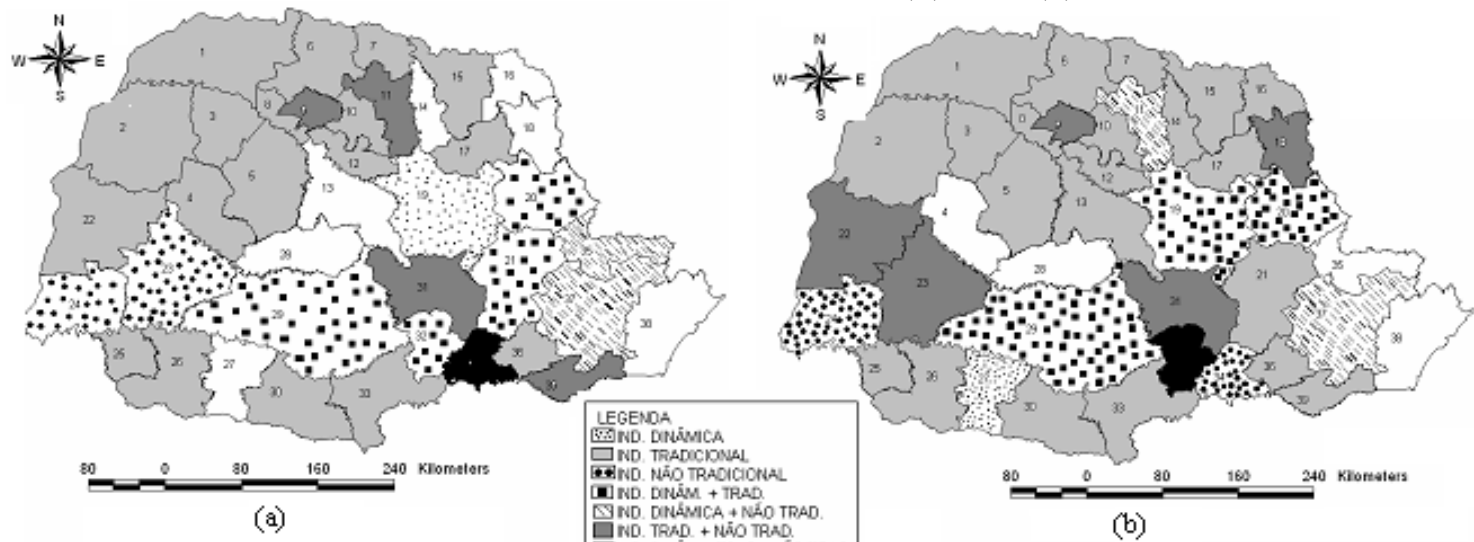

FONTE: Elaboração da Pesquisa, com legenda das microrregiões em Anexo 1.

Percebe-se que o número de microrregiões que concentravam apenas um ramo industrial aumentou no período observado, passando de 51,3\% para 61,5\%, destacando que o número de microrregiões que concentravam somente a indústria não tradicional e dinâmica não se alterou, aumentando, apenas, o número de microrregiões que concentram a indústria tradicional. Essa menor quantidade de atividades concentradas nas microrregiões não é um bom indicativo para o seu dinamismo, levando em conta que as microrregiões tornam-se mais dependentes e menos resistentes a determinadas atividades, isso porque quanto maior é o número de atividades básicas presentes numa região menor tende a ser a sua vulnerabilidade a 
eventuais crises nestes setores. Ou seja, a mono especialização deixa a região mais suscetível aos ciclos econômicos.

Dentre as microrregiões $(78,6 \%)$ que alteraram o perfil de localização das suas indústrias motoras em 2003, todas acrescentaram ou mantiveram a indústria tradicional. A região de Irati foi a única que em 2003 passou a concentrar todos os ramos industriais, com diferentes magnitudes. Já Cerro Azul foi a microrregião que mais regrediu em termos de concentração industrial, perdendo postos de trabalho em relação a 1994. Das oito microrregiões que em 1994 não detinham nenhuma indústria básica, cinco passaram a tê-las em 2003, ressaltando que apenas Pitanga, Paranaguá e Goioerê continuaram a não concentrar nenhuma dessas três indústrias. Ou seja, as indústrias tradicionais se dispersaram mais no período de análise, enquanto as indústrias mais intensivas em capital permaneceram com um perfil mais concentrado. A nova fase em que entrou a economia paranaense não alterou de forma significativa a polarização industrial no Estado. Apesar de algumas microrregiões avançarem, elas ainda estão bem aquém de Curitiba, Londrina, Maringá e Ponta Grossa em termos de crescimento industrial.

Por meio da Figura 2, tem-se o perfil locacional do Comércio/Serviço, Transporte/Comunicação e Administração Pública. Verifica-se que a região de Curitiba era a única que detinha, em 1994, esses três ramos de atividades que estimulavam de forma contundente a economia regional. Nota-se que 38,5\% das microrregiões do Paraná não detinham, em 1994, nenhum desses ramos como básicos, 38,5\% concentravam a administração pública, 23,1\% detinham como ramo básico o transporte/comunicação e 20,5\% das microrregiões concentravam o comércio/serviço, ressaltando que a região Norte era a que mais sobre-representava a administração pública.

No ano de 2003, o ramo administração pública continuou concentrado na região Norte, deslocando-se também, para o Centro do Paraná. A Figura 2 demonstra que o ramo transporte/comunicação teve maior predominância no corredor que vai de Paranaguá até Maringá, tendo dois pontos isolados na região Oeste, correspondendo às microrregiões de Foz do Iguaçu e Cascavel. 
FIGURA 2: QL MAIOR QUE UM, INDICANDO AS ATIVIDADES VOLTADAS PARA A EXPORTAÇÃO NAS MICRORREGIÕES DO PARANÁ-1994 (A), 2003 (B).

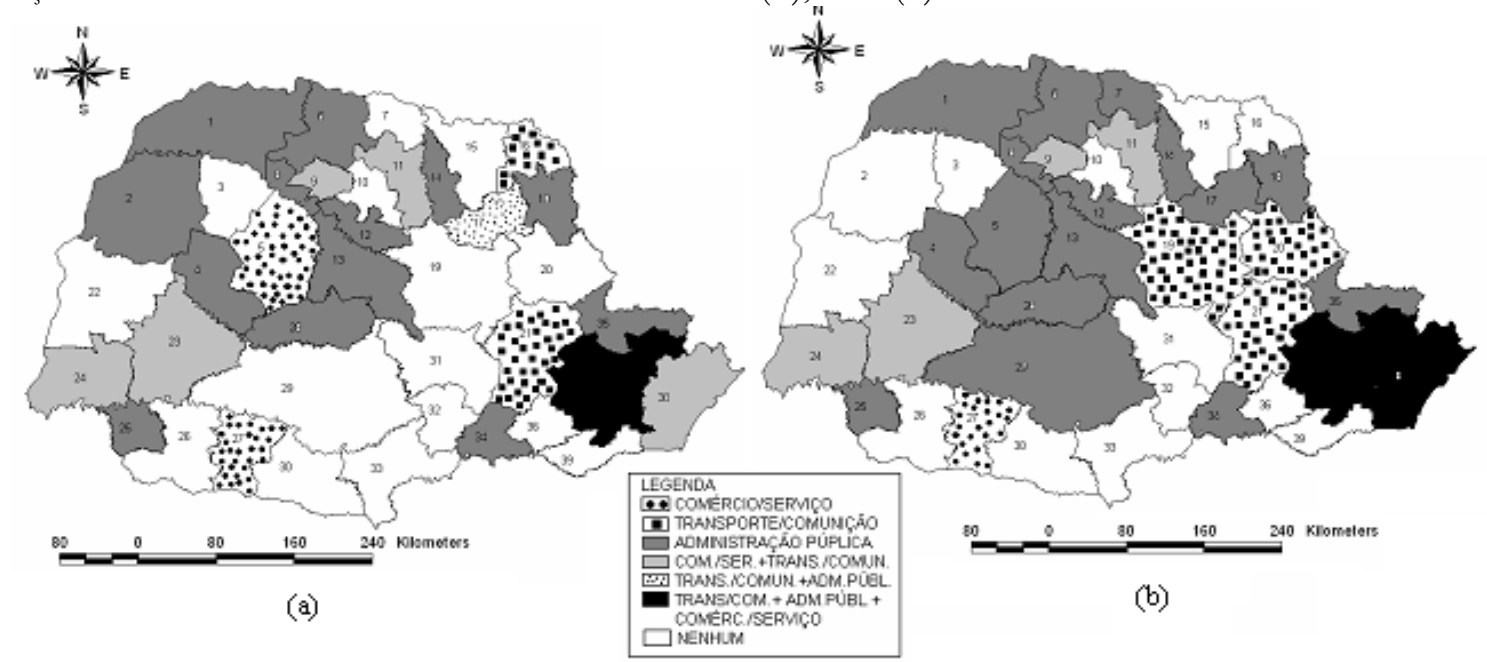

FONTE: Elaboração da Pesquisa, com legenda das microrregiões em Anexo 1

A representação acima evidencia que as microrregiões que possuíam a administração pública como ramo básico apresentaram aumento de 38,5\% para 46,2\%, diminuindo as que detinham o comércio/serviço $(17,9 \%)$ e mantendo o mesmo percentual das que tinham o transporte/comunicação como ramos básicos. Esse aumento da concentração da administração pública demonstra a sua importância na sustentação do desenvolvimento e do dinamismo local, o que é um sintoma quanto à incapacidade do setor privado em gerar empregos e renda, fazendo com que o Estado tome para si essa responsabilidade e seja, portanto, a grande alavanca do dinamismo local.

Em relação ao número de microrregiões que não possuíam nem a administração pública, comércio/serviço e nem transporte/comunicação como ramos básicos, ocorreu uma diminuição no período de 1994 a 2003, passando de 38,5\% para 33,3\%.

Por meio da Figura 3, tem-se o perfil locacional da agricultura e da agroindústria ao longo do Estado do Paraná, em que apenas cinco microrregiões não possuíam, em 1994, a agroindústria como ramo motor, as quais concentravam, por sua vez, o setor terciário da economia (Figura 2).

No ano de 1994, praticamente todas as microrregiões $(69,2 \%)$ tinham a agroindústria como ramo básico e $61,5 \%$ concentravam a agricultura. Nota-se que 70,8\% das microrregiões que tinham como ramo básico da economia a agricultura apresentavam também a agroindústria. Esta constatação é importante, pois é a evidência de uma proximidade entre a agricultura e a agroindústria, o que sugere a existência de uma agregação de valor por esta última, com um possível aumento da industrialização no campo. 
FIGURA 3: PERFIL LOCACIONAL DAS ATIVIDADES PRODUTIVAS NO PARANÁ: MICRORREGIÕES COM ATIVIDADES MAIS CONCENTRADAS (QL>1)-1994 (A) E 2003 (B).

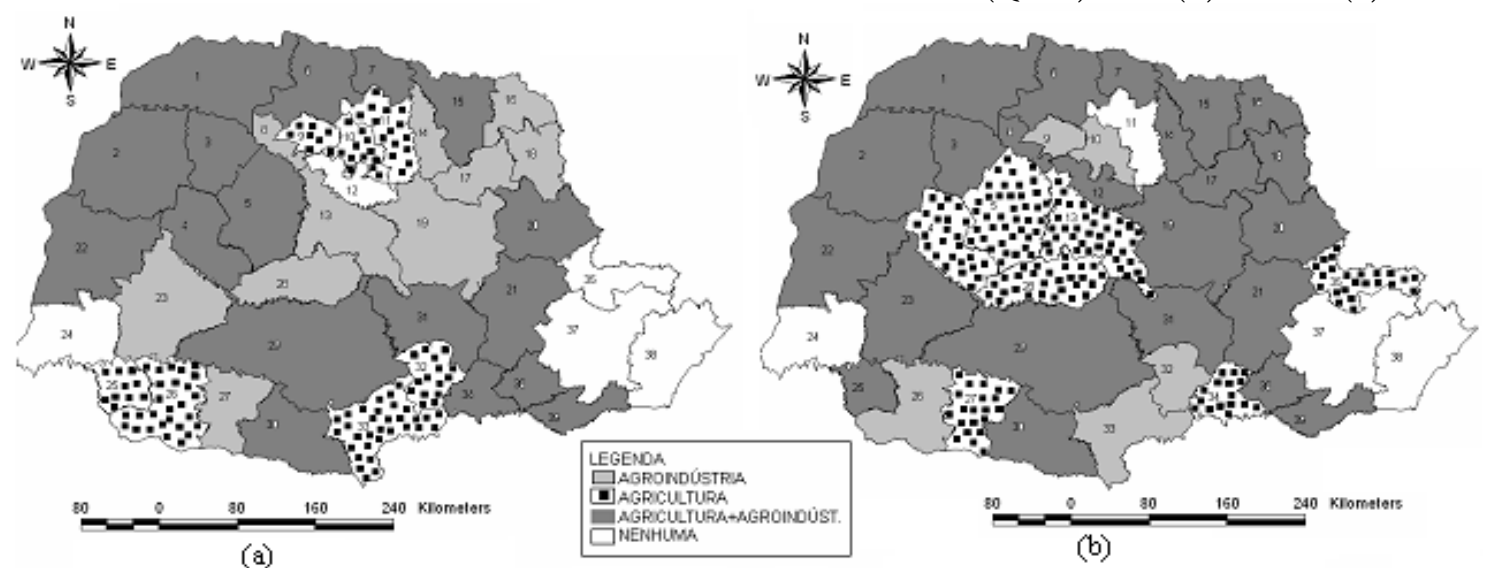

FONTE: Elaboração da Pesquisa, com legenda em Anexo 1.

A Figura 3 demonstra que 56,4\% das microrregiões do Paraná tinham a agricultura e a agroindústria, juntas, como atividades motoras em 2003. O percentual de microrregiões que tinham a agricultura como ramo básico aumentou, passando de $61,5 \%$ para $76,9 \%$, enquanto que o percentual que possuía a agroindústria como ramo básico praticamente não se alterou, passando de 69,2\% para 71,8\%. Das microrregiões que concentravam a agricultura, 76,7\% concentravam também a agroindústria, indicando uma maior agregação de valor dos produtos primários nas próprias regiões. Isso reflete a diminuição da dependência quanto ao preço recebido ao comercializar simples commodities.

Analisando a distribuição espacial da agricultura e da agroindústria e o seu grau de importância para cada microrregião nos anos de 1994 e 2003, observa-se que 50\% das microrregiões que alteraram os seus ramos básicos apresentaram aumento, 31,8\% apenas alteraram e $18,2 \%$ perderam um dos ramos ou os dois juntamente, sendo este o caso de Londrina.

\section{ESPECIALIZAÇÃO, REESTRUTURAÇÃO E CONCENTRAÇÃO DAS ATIVIDADES PRODUTIVAS NO PARANÁ}

No ano de 1994, o ramo mais disperso no Estado do Paraná era a agricultura, seguida pela agroindústria, indústria tradicional, indústria dinâmica, administração pública, transporte/comunicação, indústrias não tradicionais e comércio/serviços. Desta forma, neste mesmo ano, a agricultura apresentava um padrão de dispersão regional mais intenso que o conjunto de todos os demais ramos e o comércio/serviço estava distribuído praticamente da mesma forma que o conjunto dos demais ramos de atividades ao longo do Paraná.

No ano de 2003, a agricultura continuou sendo o setor mais difuso no Estado, porém, em menor grau, seguido da agroindústria, da indústria tradicional, indústria dinâmica, 
transporte/comunicação, administração pública, indústrias não tradicionais e comércio/serviços.

Comparando os dois períodos, percebe-se que a ordem de concentração permaneceu praticamente a mesma, exceto pela troca de posição entre os ramos administração pública e transporte/comunicação, em que, este último concentrou-se mais em detrimento do primeiro. Apenas os ramos transporte/comunicação e comércio/serviços tiveram o valor da sua concentração relativa aumentada no decorrer deste período.

Verifica-se ainda que em 1994, 15,4\% das microrregiões apresentavam estruturas produtivas mais especializadas face ao conjunto da economia do Paraná como um todo. Nota-se que Cianorte, Florai e Porecatu tinham como principal polo de especialização a agricultura. Em Cianorte esse perfil mudou se comparado aos índices de 2003. Já Palmas e União da Vitória concentravam, de forma mais acentuada, a agroindústria e Cerro Azul a indústria dinâmica. Já, outras $15,4 \%$ das microrregiões apresentavam um padrão de especialização muito próximo em relação ao espaço de referência (o Estado como um todo).

Para 2003, houve uma diminuição do percentual das microrregiões que apresentavam uma estrutura produtiva mais especializada que as demais microrregiões do Estado, passando de $15,4 \%$ para 5,1\%, o que evidencia certa melhoria na homogeneidade das atividades desenvolvidas no Estado. Mesmo assim, em termos de magnitude as atividades continuam com um padrão de localização bem distinto.

Por fim, na Figura 4 apresenta-se a reestruturação das atividades produtivas das microrregiões do Paraná, inferindo que no período de 1994 a 2003 apenas 5,1\% delas tiveram elevada reestruturação na sua composição setorial. Mais precisamente, Telêmaco Borba e Cerro Azul foram as que apresentaram maiores valores para esse coeficiente. Porém, o sentido da mudança estrutural nessas duas microrregiões foi totalmente oposto: em Telêmaco Borba a reestruturação produtiva veio emanada de aspectos positivos, mantendo os ramos concentrados de 1994 e aumentando outros setores; contrariamente, para Cerro Azul a reestruturação trouxe aspectos negativos, perdendo a indústria dinâmica e a não tradicional.

As microrregiões paranaenses praticamente não alteraram a sua composição setorial, em que, 38,5\% tiveram um valor do coeficiente de reestruturação abaixo de 0,10 e outras 43,6\% tiveram um coeficiente entre 0,10 e 0,17, indicando uma baixa modificação na composição setorial durante o período de nove anos. Assim, este baixo coeficiente de reestruturação para a maioria das microrregiões do Paraná pode indicar uma considerável estabilidade estrutural, acompanhada de taxas de incorporação elevadas ou totalmente baixas. 
FIGURA 4: REESTRUTURAÇÃO PRODUTIVA DAS MICRORREGIÕES DO PARANÁ-1994 A 2003

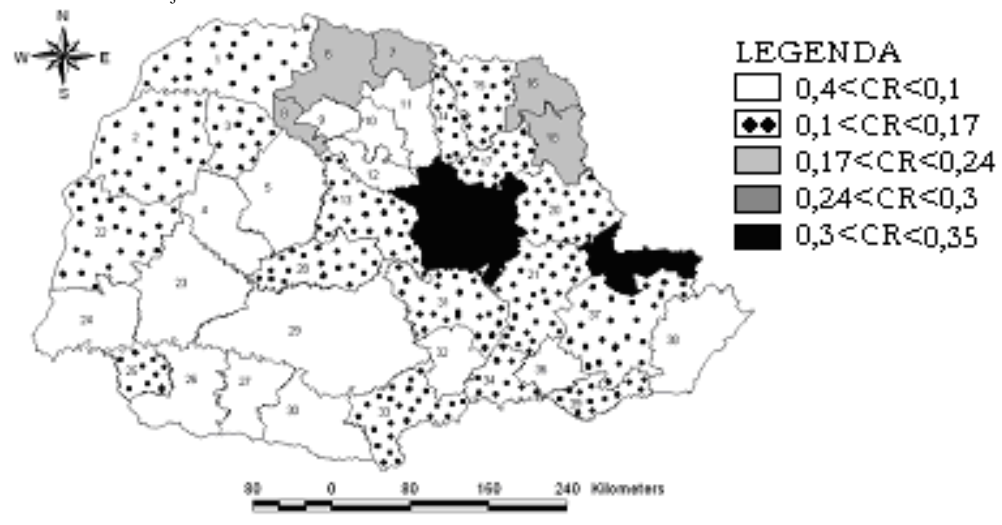

FONTE: Elaboração da Pesquisa, com legenda em Anexo 1.

\section{CONCLUSÃO}

Esta pesquisa teve como objetivo analisar a concentração de determinadas atividades nas microrregiões do Paraná, em 1994 e 2003. Observou-se que neste período o número de microrregiões que detinham a indústria tradicional, a não tradicional, a administração pública, a agricultura e a agroindústria como atividades motoras aumentou, permanecendo praticamente constante as que tinham transportes/comunicação e, diminuindo o número de microrregiões que localizavam de forma significativa o comércio/serviços e a indústria dinâmica como setores básicos. Essa queda de participação, essencialmente deste último ramo, evidencia que na nova economia paranaense a presença dos setores industriais mais intensivos em capital (indústria dinâmica) não se deu homogeneamente em todas as microrregiões do Estado, concentrando-se principalmente naquelas em que já se tinha tal ramo como básico.

Quando analisado apenas o setor industrial, constatou-se que o número de microrregiões que detinham apenas uma indústria como básica aumentou, todavia, mensurando todos os ramos identificou-se que as microrregiões aumentaram as atividades voltadas para a exportação. Assim, pode-se dizer que as microrregiões tornaram-se menos vulneráveis e elevaram suas possibilidades de desenvolvimento local, substituindo em algumas regiões, o setor industrial por outros ramos produtivos. Porém, muitas microrregiões substituíram a concentração industrial pela concentração da administração pública, tornando esta parte da sustentação do dinamismo local, fato que indica uma perda de capacidade do setor privado em gerar emprego e conduzir o desenvolvimento. 


\section{REFERÊNCIAS}

COSTA, J. S. (coord.). Compêndio de Economia Regional. Coimbra: APDR, 2002.

HADDAD, P. R. (org.). Economia Regional: Teorias e Métodos de Análise. Fortaleza: BNB, 1989.

IBGE. Pesquisa Industrial. Rio de Janeiro, v.18, 1999, p.1-247.

LOURENÇO, G.N. Cenários de compreensão da dinâmica econômica paranaense. In: CARIO, S.A.F.; PEREIRA, L.B.; BROLLO, M.X.(org.). Economia Paranaense: estudos de ramos selecionados. Florianópolis: UFSC, programa de Pós Graduação em Economia, 2002, p.19-36.

\section{ANEXO 1: Legenda das Microrregiões Paranaenses}

\begin{tabular}{|llll|}
\hline 10: Apucarana & 12: Faxinal & 20: Jaguariaíva & 7: Porecatu \\
14: Assai & 8: Florai & 36: Lapa & 31: Prudentópolis \\
6: Astorga & 24: Foz do Iguaçu & 11: Londrina & 39: Rio Negro \\
5: Campo Mourão & 26: Francisco Beltrão & 9: Maringá & 34: São Mateus do Sul \\
25: Capanema & 4: Goioerê & 30: Palmas & 19: Telêmaco Borba \\
23: Cascavel & 29: Guarapuava & 38: Paranaguá & 22: Toledo \\
35: Cerro Azul & 17: Ibaiti & 1: Paranavaí & 2: Umuarama \\
3: Cianorte & 32: Irati & 27: Pato Branco & 33: União da Vitória \\
15: Cornélio Procópio & 13: Ivaiporã & 28: Pitanga & 18: Wenceslau Braz \\
37: Curitiba & 16: Jacarezinho & 21: Ponta Grossa & \\
\hline
\end{tabular}


